\title{
DIRECTION AND RATE OF SOCKET WEAR IN CHARNLEY LOW-FRICTION ARTHROPLASTY
}

\author{
B. M. WROBLEWSKI
}

From The Centre for Hip Surgery, Wrightington Hospital, Wigan

\begin{abstract}
Twenty-two high-density polyethylene sockets from Charnley low-friction arthroplasties have been studied. Acrylic casts and shadowgraph techniques were used to measure both the real and radiographic rates of wear; these rates showed a significant correlation. In the sagittal plane, nine of the sockets had worn lateral to a line drawn vertically from the centre of curvature of the socket, 12 had worn medial to that line and only one was worn exactly in the line. In the coronal plane, nine sockets had worn in front of a similar vertical line, two behind that line and 11 had worn exactly in the line. Evidence of impingement of the neck of the stem onto the rim of the socket was found in 14 patients; this is considered to be one of the causes of socket loosening. The obvious solution is to reduce the diameter of the neck of the stem from $12.5 \mathrm{~mm}$ to $10 \mathrm{~mm}$; provided that it is made of cold-formed, high nitrogen-content stainless steel, this narrower neck is strong enough not to fracture.
\end{abstract}

Polytetrafluorethylene (PTFE), the first plastic used for the socket in total hip arthroplasty, was abandoned because of rapid wear and adverse tissue reaction (Charnley 1963). A later study of PTFE sockets removed at revision surgery established that the wear did not take place randomly; the metal prosthetic head bored into the plastic, creating for itself a cylindrical path (Charnley, Kamanger and Longfield 1969). The volume of the plastic displaced was directly proportional to the depth of its penetration by the metal head. Charnley $e t$ al. considered that the wear was related to the level of functional activity rather than to the weight of the patients. In order to reduce the volume of the plastic debris, the smallest possible diameter of the head was needed; but if this was less than $22.25 \mathrm{~mm}$, dislocation or rapid penetration of the plastic seemed likely to occur.

With the introduction of high-density polyethylene (HDP) in 1962, the socket took a longer time to wear and the opportunity of examining sockets removed from living people was lost. In order to measure the wear of HDP during life, a semicircular radiographic marker was placed on the socket in the coronal plane and was subsequently used for measurements (Charnley and Cupic 1973; Charnley and Halley 1975; Griffith et al. 1978).

In their review of low-friction arthroplasty (LFA) after 9 to 10 years, Charnley and Cupic (1973) reported . that the average wear of the HDP measured from radiographs was $0.12 \mathrm{~mm}$ in one year with a range of $0.09 \mathrm{~mm}$ to $0.3 \mathrm{~mm}$. They found no obvious correlation between

B. M. Wroblewski, FRCS. Consultant Orthopaedic Surgeon Centre for Hip Surgery, Wrightington Hospital, Wigan, Lancashire WN6 9EP. England.

(c) 1985 British Editorial Society of Bone and Joint Surgery $0301-620 \times / 85 / 5151 \$ 2.00$ wear and physical activity, nor with the weight of the patient, and concluded that differences in the rate of wear were probably due to variations in quality of the HDP. After extensive investigations, however, Clarke et al. (1976) found that wear measurements could not be made from clinical radiographs, a view with which Beckenbaugh and Ilstrup (1978) and Rose and Radin (1982) agreed. Their criticisms of Charnley and Cupic's 1973 studies were probably justified, as the radiographic magnification had not been taken into account, but Charnley et al. (1978) later pointed out that such measurements were meaningful provided that the wear marker was not more than $10^{\circ}$ from the coronal plane and radio-opaque cement was used. In their subsequent studies the radiographic magnification was taken into account.

From the studies of Charnley and Cupic (1973), Charnley and Halley (1975) and Griffiths et al. (1978), the average rate of wear was considered to be between $0.07 \mathrm{~mm}$ and $0.15 \mathrm{~mm}$ per year, though some sockets wore as much as $0.3 \mathrm{~mm}$ per year. Charnley and Halley (1975) pointed out that $3.4 \%$ of the sockets wore medial to a line drawn vertically from the centre of curvature of the socket, while $64.4 \%$ wore lateral to this line; in $32.2 \%$, the wear was in the vertical line itself. They also speculated on the clinical implications of these results and suggested that more than $5 \mathrm{~mm}$ of wear might cause impingement of the neck of the stem against the rim of the socket, leading to socket loosening.

There have so far been no reports which correlate the real with the radiographic measurements of socket wear. We have therefore conducted such a study in patients with normal function, documented clinical history and a reasonably long follow-up, and have attempted to answer certain fundamental questions: 


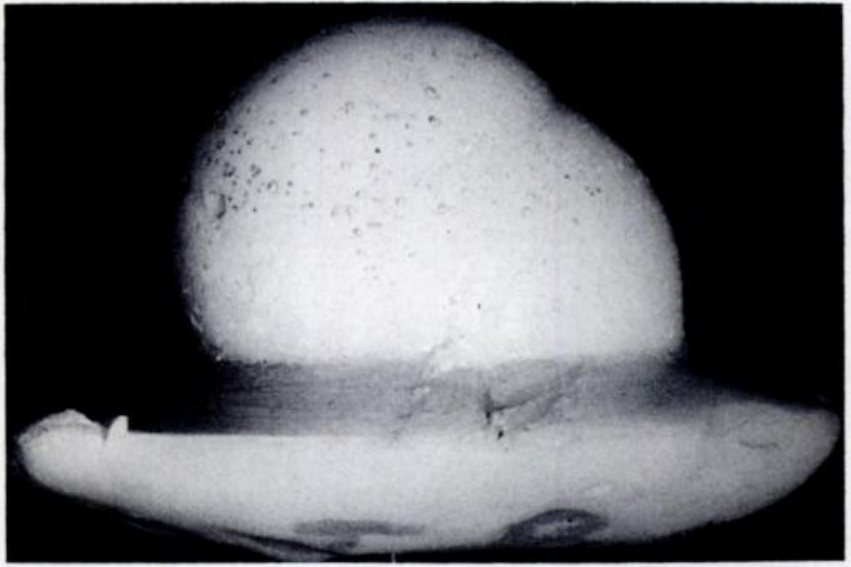

Fig. 1

Case 19. An acrylic cast of the socket showing the path of wear.

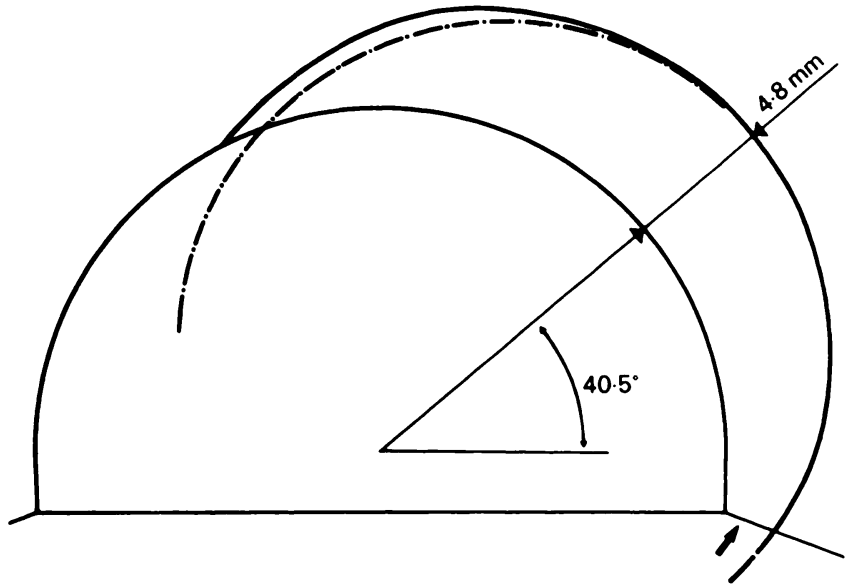

Fig. 2

Case 20. A shadowgraph tracing of the socket; the depth of wear is $4.8 \mathrm{~mm}$ and the angle of wear, 40.5 . The direction of wear is exactly in the coronal plane. The arrow indicates the erosion of the margin of the socket caused by the encroachment of the worn volume onto the socket face.

Table I. Details of the patients, sockets and shadowgraphs studied

\begin{tabular}{|c|c|c|c|c|c|c|c|c|c|c|c|c|}
\hline \multirow[b]{2}{*}{ Case } & \multirow[b]{2}{*}{ Age } & \multirow[b]{2}{*}{ Sex } & \multirow[b]{2}{*}{ Diagnosis } & \multirow[b]{2}{*}{$\begin{array}{l}\text { Weight } \\
\text { (kg) }\end{array}$} & \multirow{2}{*}{$\begin{array}{l}\text { Time to } \\
\text { revision } \\
\text { (months) }\end{array}$} & \multirow[b]{2}{*}{$\begin{array}{l}\text { Reason for } \\
\text { revision }\end{array}$} & \multicolumn{2}{|c|}{ Wear (mm) } & \multicolumn{4}{|c|}{ Clinical results up to revision* } \\
\hline & & & & & & & $\begin{array}{l}\text { Radio- } \\
\text { graphic }\end{array}$ & Real & Pain & $\begin{array}{l}\text { Func- } \\
\text { tion }\end{array}$ & $\begin{array}{l}\text { Move- } \\
\text { ment }\end{array}$ & $\begin{array}{l}\text { Opposite } \\
\text { hip }\end{array}$ \\
\hline 1 & 66 & $\mathbf{F}$ & $\mathrm{CDS} / \mathrm{OA}$ & 70 & 132 & Fractured stem & 0.83 & 1.2 & 6 & 6 & 5 & LFA \\
\hline 2 & 68 & $\mathbf{M}$ & $\mathbf{O A}$ & 72.3 & 108 & Fractured stem & 1.96 & 2.55 & 6 & 6 & 6 & LFA \\
\hline 3 & 68 & $\mathbf{M}$ & $\mathbf{O A}$ & 76.4 & 65 & Loose stem & 1.53 & 1.14 & 6 & 6 & 6 & LFA \\
\hline 4 & 66 & $\mathbf{M}$ & $\mathbf{O A}$ & 100 & 99 & Fractured stem & 0.42 & 0.23 & 6 & 6 & 5 & LFA \\
\hline 5 & 60 & $\mathbf{F}$ & $\mathbf{O A}$ & 60.5 & 46 & Fractured stem & 0.4 & 0.2 & 6 & 6 & 6 & Normal \\
\hline 6 & 71 & $\mathbf{M}$ & $\mathbf{O A}$ & 116.4 & 69 & Fractured stem & 0.4 & 0.2 & 6 & 6 & 5 & Normal \\
\hline 7 & 68 & $\mathbf{M}$ & $\mathbf{O A}$ & 76.4 & 72 & Fractured stem & 1.02 & 0.1 & 6 & 5 & 5 & Normal \\
\hline 8 & 64 & $\mathbf{M}$ & $\mathbf{O A}$ & 60.5 & 96 & Fractured stem & 1.46 & 0.91 & 6 & 6 & 6 & LFA \\
\hline 9 & 50 & $\mathbf{F}$ & Fracture/dislocation & 92.3 & 96 & Fractured stem & 1.51 & 1.42 & 6 & 6 & 6 & LFA \\
\hline 10 & 62 & $\mathbf{M}$ & $\mathbf{O A}$ & 90.9 & 113 & Fractured stem & 1.86 & 1.6 & 6 & 6 & 5 & LFA \\
\hline 11 & 71 & $\mathbf{M}$ & OA & 68.2 & 63 & Fractured stem & - & 0.61 & 6 & 6 & 6 & Normal \\
\hline 12 & 77 & $\mathbf{M}$ & $\mathbf{O A}$ & 82.7 & 108 & Loose stem & 2.08 & 2.4 & 6 & 6 & 5 & LFA \\
\hline 13 & 74 & $\mathbf{F}$ & $\mathbf{O A}$ & 84.5 & 112 & Fractured stem & 0.85 & 0.4 & 6 & 6 & 6 & LFA \\
\hline 14 & 70 & $\mathbf{M}$ & OA & 85.9 & 54 & Fractured stem & 1.24 & 0.3 & 6 & 6 & 5 & $\begin{array}{l}\text { Early } \\
\mathrm{OA}\end{array}$ \\
\hline 15 & 54 & $\mathbf{F}$ & $\mathbf{O A}$ & 77.3 & 56 & Loose stem & 0.98 & 1.2 & 6 & 6 & 6 & Normal \\
\hline 16 & 65 & $\mathbf{M}$ & Paget's disease & 76.4 & 96 & Fractured stem & 1.83 & 1.8 & 6 & 6 & 5 & Normal \\
\hline 17 & 63 & $\mathbf{M}$ & $\mathbf{O A}$ & 73.2 & 84 & Fractured stem & 0.83 & 0.56 & 6 & 6 & 6 & Normal \\
\hline 18 & 55 & $\mathbf{M}$ & OA & 111.4 & 36 & Loose stem & 0.42 & 0.2 & 6 & 6 & 6 & Normal \\
\hline 19 & 39 & $\mathbf{F}$ & Still's disease & 57.3 & 110 & Loose cup & 3.52 & 4.8 & 5 & 5 & 6 & LFA \\
\hline 20 & 39 & $\mathbf{F}$ & Still's disease & 57.3 & 110 & Loose cup & 3.73 & 4.8 & 5 & 5 & 6 & LFA \\
\hline 21 & 69 & $\mathbf{M}$ & OA & 85.9 & 110 & Fractured stem & 3.36 & 2.6 & 6 & 6 & 6 & Normal \\
\hline 22 & 73 & $\mathbf{M}$ & OA & 72.7 & 54 & Loose stem & 3.05 & 1.1 & 6 & 6 & 6 & Normal \\
\hline
\end{tabular}

* The scoring system used (1-6) was devised by Merle d'Aubigné and Postel (1954) and modified by Charnley (1972): 1, severely affected; 6, normal $\mathrm{CDS}$, congenital dislocation or subluxation

OA, osteoarthritis

LFA, low-friction arthroplasty 
what is the correlation between the real and the radiographic measurements of the HDP wear; what is the rate of HDP wear in patients with normal function; what are the possible mechanical consequences of such wear; and finally, could the answer to these questions be used to predict the clinical outcome and to give the clinician some guidelines as to selection of patients or changes in design of components?

The study did not attempt to distinguish between real wear and creep, focusing instead only on the depth of penetration of the HDP by the metal head. It is appreciated that tissue reaction to plastic debris may be important, but that is outside the scope of the present study.

\section{MATERIAL AND METHOD}

At revision operations the sockets were examined for any movement at the bone-cement interface, using the screw technique (Wroblewski 1982b). Before extraction, the lateral and the anterior parts of the face of the socket were marked for orientation in the manner described by Charnley (1979). In order to measure the depth of wear, acrylic casts were made (Fig. 1); these showed the marks on the socket face and so defined the precise orientation. In addition, the casts were examined using a shadowgraph technique, assessing the direction and depth of wear (Fig. 2) by measuring the distance between the wire marker and the head of the femoral component on the first and the last radiograph. The greatest difference between the two readings was taken as the measurement of radiographic wear after applying a correction factor for magnification; this was based on comparing the known diameter of the metal femoral head $(22.25 \mathrm{~mm})$ with that measured on each radiograph.

At the end of the study a theoretical model was set up, using the shadowgraph technique, to measure the effects of the depth and angle of wear on the range of flexion. This was done in order to predict the degree of movement restriction at various depths and angles of wear and the likelihood of impingement which might contribute to socket loosening.

\section{RESULTS}

All the revisions were carried out by the author; the findings are shown in Table $I$. The clinical results were obtained from the patients' charts, where they had been recorded using Merle d'Aubigné and Postel's scale (1954) as modified by Charnley (1972).

Correlation between radiological and real wear. For the whole group of 22 paired observations, a highly significant result was found $(P<0.001)$, indicating an extremely good correlation between radiological and real measurements of wear. With less than $2 \mathrm{~mm}$ of real wear the radiological measurement overestimated the result, while above $2 \mathrm{~mm}$ the radiological wear was underestimated (Fig. 3).

Rate of wear. The mean rate of real wear of the HDP socket was $0.19 \mathrm{~mm}$ per year with a range of $0.017 \mathrm{~mm}$ to

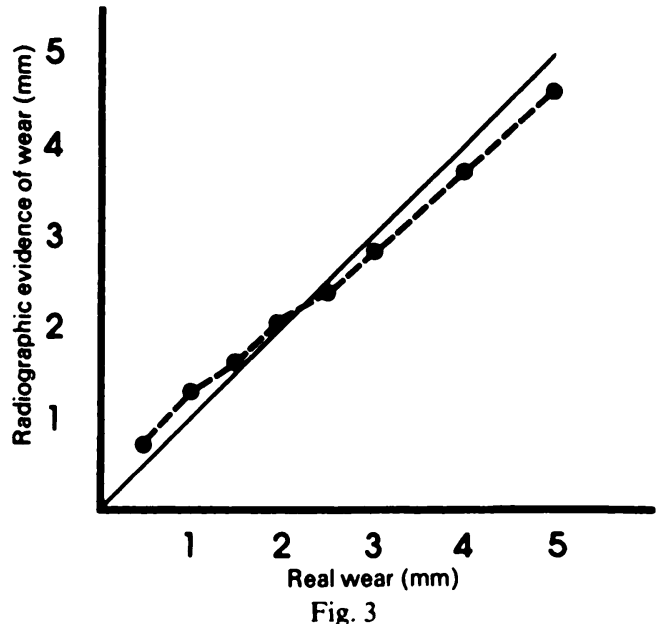

Correlation between radiographic evidence of wear and real wear of the socket. The solid line indicates the expected results, while the broken line indicates the results found from the study.

$0.52 \mathrm{~mm}$. The mean rate of wear measured radiologically was $0.21 \mathrm{~mm}$ per year, with a range from zero to $0.41 \mathrm{~mm}$. The relationship between real wear and time for the whole group is shown in Figure 4. For the 15 patients with fracture of the stem a significant correlation between time and wear was found $(P<0.001)$. It was considered that, in these 15 , function was normal up to the time of fracture (Wroblewski 1982a); since fracture is a more definite event than loosening, they provide a better index of the rate of socket wear than those from patients operated on for loosening. The graph indicates the rate of wear only for the period under study and not the rate of wear from the time of operation.

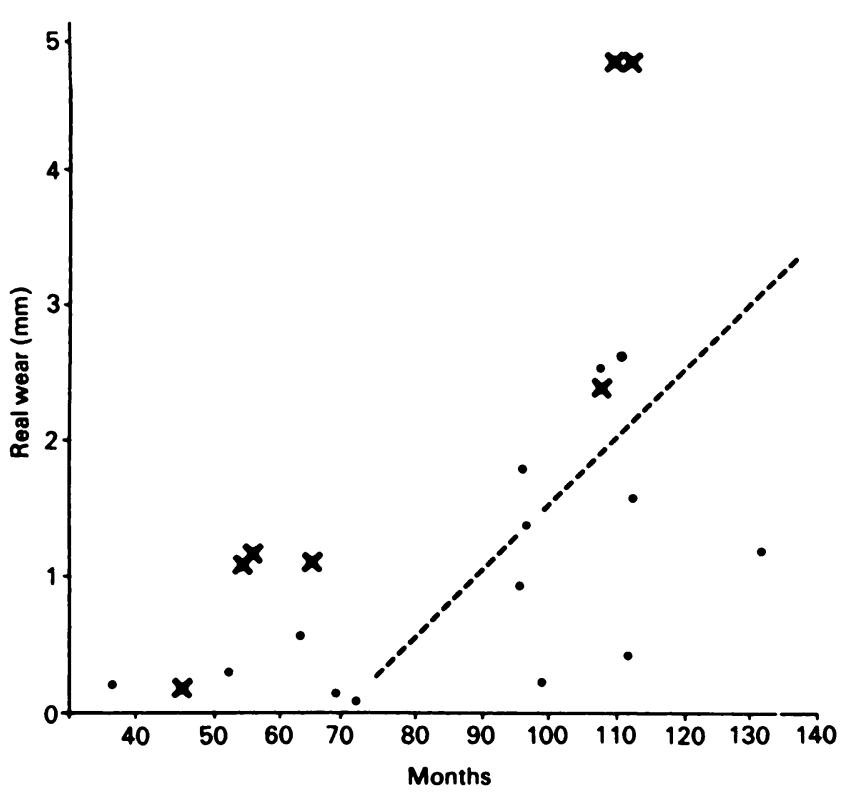

Fig. 4

Relationship between time and rate of wear: the dots indicate patients with fractured stems, while crosses indicate those with a loose cup or stem. The broken line shows the time-wear rate for cases with a fractured stem. 


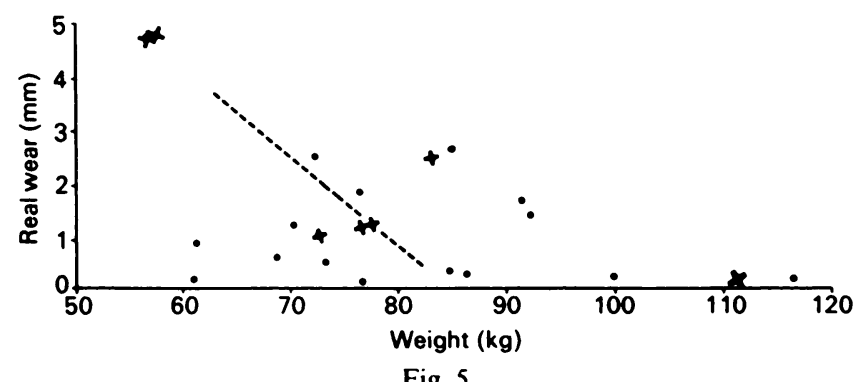

Fig. 5

Relationship between weight and rate of wear (dots, fractured stems crosses, loose cups or stems). The broken line is the curve for the patients with fractured stems.

Direction of wear. The inclination of the socket (angle open laterally) measured between $40^{\circ}$ and $60^{\circ}$ (average $48^{\circ}$ ). In nine of the sockets the path of wear was lateral to a line drawn vertically from the centre of the curvature of the socket, and the most extreme path was found at the very rim of the socket in two cases; one of the sockets in this group wore within 3 of the vertical. Twelve sockets wore medial to the vertical: in two the path of wear was within 5 of the line and the most extreme path was $34.5^{\circ}$ medial to the vertical, within 5.5 of the centre line of the socket. Only one socket had worn exactly vertically. Nine sockets wore anterior to the coronal plane while two wore posterior to it. These discrepancies in the direction of wear in the coronal plane may account for the individual differences between the real and the radiographic wear measurements.

Relationship between patients' weight and real wear of the socket. This is shown in Figure 5. For the 15 fractured stems there was an insignificant correlation between weight and wear. Although the slope of the graph suggests that wear was greater in lighter patients, the $P$ value is not significant and the correlation is therefore not meaningful. It is almost certain that the product of time and weight will prove to be more significant in this context.

Impingement. Erosion of the rim of the socket as seen on shadowgraphs taken from the acrylic casts was accepted as evidence of impingement (Fig. 2). Excluding two cases (Case 4 and Case 15) where the wear was on the rim of the socket, 14 showed some degree of erosion of the rim; the lowest depth of wear in this group was $0.56 \mathrm{~mm}$ (Case 17). In six cases there was no rim erosion. The greatest depth of wear in this group was $0.4 \mathrm{~mm}$ (Case 13). It would appear that, with between $0.4 \mathrm{~mm}$ and $0.56 \mathrm{~mm}$ of wear, some degree of impingement of the neck of the stem onto the rim of the socket is to be expected.

Results of the theoretical model. All the measurements for the range of angular movement were made on the assumption that the direction of wear is most likely to be in only the coronal plane but would be at various angles from the centre of the socket. The results of varying depths of penetration on the restriction of angular movements are seen in Figure 6; these show that the more central the wear, the greater the restriction in the angle of movements, while the more peripheral the wear, the less

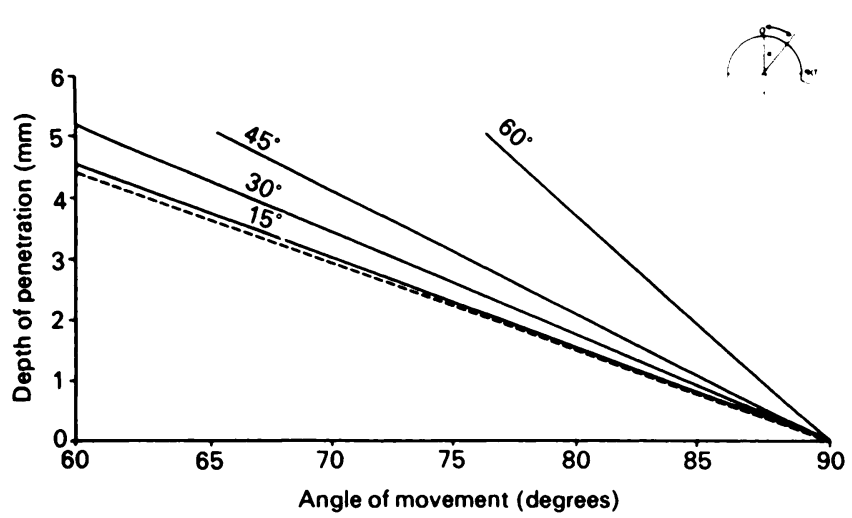

Fig. 6

Results of the theoretical model, illustrating the effect of the depth of penetration of the HDP socket on angular movements of the arthroplasty. Measurements were taken from the centre of the socket to the periphery at $15,30,45$ and 60 . indicated by the four solid lines. The dotted line represents 0 .

the restriction. The calculation took into account that erosion of the margin of the socket will take place as the depth of socket penetration increases (Fig. 2). With a $5 \mathrm{~mm}$ depth of wear, at 45 , the restriction will be about $25^{\circ}$.

Reduction of the diameter of the neck of the stem from the present $12.5 \mathrm{~mm}$ to $10 \mathrm{~mm}$ would allow a probable increase of 18 of angular movement before impingement (Fig. 7) (Wroblewski 1985a). Assuming again the 45 angle of wear, this would result in there being $3 \mathrm{~mm}$ of plastic available before the angular movements were reduced to the 90 available with the present design. Accepting the results of the present study, this would amount to adding between 6 years (as in Cases 19 and 20) and 180 years (Case 7) with an average of 15.8 years, to the life of the socket. Since there is a correlation between the depth of socket wear and the incidence of socket loosening (Wroblewski $1985 \mathrm{~b}$ ), the $20 \%$ reduction of the neck diameter is strongly recommended. Such a reduction can be compensated by the use of coldformed, high nitrogen-content stainless steel (Ortron

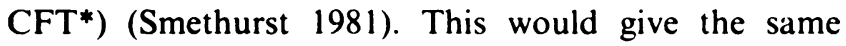
* Charles F. Thackray Ltd, Leeds

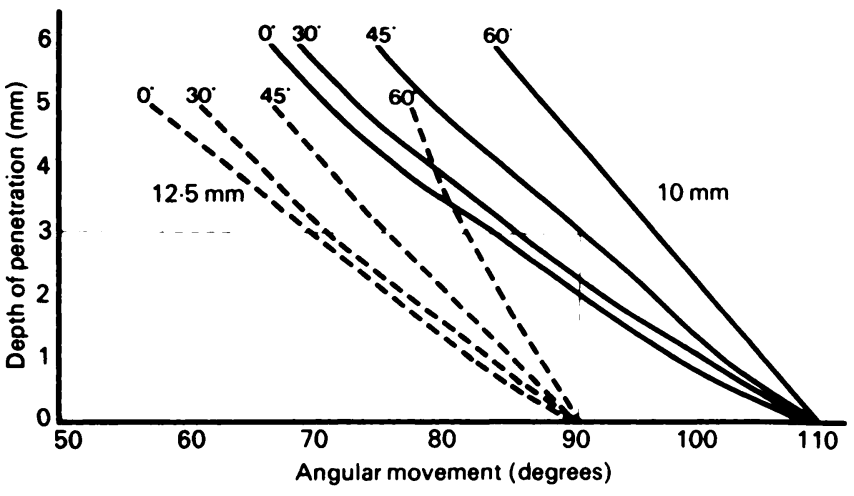

Fig. 7

Reducing the diameter of the neck of the femoral component from $12.5 \mathrm{~mm}$ (broken line) to $10 \mathrm{~mm}$ (solid line) increases the arthroplasty's range of angular movements: the moment of impingement would thus occur later. 
strength as the 316L's thicker neck, which has never failed in clinical practice.

\section{DISCUSSION}

With the extensive use of HDP for joint replacement, it is essential that accurate yet simple methods of wear measurements should be established. This present study confirms that the radiographic method is reliable provided that each reading is corrected for magnification and the known diameter of the head of the femoral component is used as a standard. The average rate of wear was $0.19 \mathrm{~mm}$ per year, which correlates closely with previous findings. The exceptionally high wear rate of $0.52 \mathrm{~mm}$ per year found in one patient is disturbing, especially as she was a young active patient with burnt-out Still's disease. At the other extreme, the wear of $0.1 \mathrm{~mm}$ in six years in another patient (a rate of $0.017 \mathrm{~mm}$ per year) is difficult to explain.

This extreme variation between cases needs urgent research. If it derives from differences in the quality of HDP, then the material needs to be standardised; if it is thought to be a result of particulate debris between socket and head, then evidence from clinical cases should be sought.

The relationship between the patient's activity and wear also needs to be quantified accurately. While these and other investigations are being carried out and methods of improved socket fixation are being implemented, the obvious step is to reduce the diameter of the femoral neck component while retaining its strength; this can be achieved by using cold-formed, high nitrogen-content stainless steel.
My sincere thanks to the Charles F. Thackray Company Ltd of Leeds for their help in the study, and to Dr R. W. White for his detailed statistical analysis.

\section{REFERENCES}

Beckenbaugh RD, Ilstrup DM. Total hip arthroplasty: a review of three hundred and thirty-three cases with long follow-up. J Bone Joint Surg $[$ Am $]$ 1978;60-A:306-13.

Charnley J. Tissue reactions to polytetrafluorethylene. Lancet 1963;ii: 1379.

Charnley J. The long-term results of low-friction arthroplasty of the hip performed as a primary intervention. J Bone Joint Surg $[B r]$ 1972:54-B:61-76.

Charnley J. Low friction arthroplasty of the hip: theory and practice. Berlin etc: Springer-Verlag. 1979:237 9.

Charnley J, Cupic Z. The nine and ten-year results of the low-friction arthroplasty of the hip. Clin Orihop 1973;95:9-25.

Charnley J, Halley DK. Rate of wear in total hip replacement. Clin Orihop 1975;112:170-9.

Charnley J, Kamangar A, Longfield MD. The optimum size of prosthetic heads in relation to the wear of plastic sockets in total replacement of the hip. Med Biol Engin 1969;7:31-9.

Clarke IC, Black K, Rennie C, Amstutz HC. Can wear in total hip arthroplasties be assessed from radiographs? Clin Orthop 1976; $121: 126-42$.

Griffith MJ, Seidenstein MK, Williams D, Charnley J. Socket wear in Charnley low friction arthroplasty of the hip. Clin Orthop 1978; 137:37-47.

Merle d'Aubigné R, Postel M. Functional results of hip arthroplasty with acrylic prosthesis. J Bone Joint Surg [Am] 1954;36-A:451-75.

Rose RM, Radin EL. Wear of polyethylene in the total hip prosthesis. Clin Orthop 1982;170: 107-15.

Smethurst E. A new stainless steel alloy for surgical implants compared to 316 S12. Biomaterials $1981 ; 2$ : 116-9.

Wroblewski BM. Revision surgery in total hip arthroplasty: surgical techniques and results. Clin Orthop 1982a;170:56-61.

Wroblewski BM. Fractured stem in total hip arthroplasty: a clinical review of 120 cases. Acta Orthop Scand 1982b;53:279-84.

Wroblewski BM. Charnley low-friction arthroplasty: review of the past, present status, prospects for the future. Clin Orthop 1985a: in press.

Wroblewski BM. Fifteen to 21-year results of the Charnley low-friction arthroplasty. Clin Orthop 1985b: in press. 